\title{
Influence of bimoment restraints on load-bearing capacity of steel I-beams
}

\author{
K. Wierzbicki \\ Faculty of Civil and Environmental Engineering, West Pomeranian University of Technology, Szczecin, \\ Poland \\ M. Szumigała \\ Faculty of Civil and Transport Engineering, Poznan University of Technology, Poznańn, Poland
}

\begin{abstract}
The study presents the results of steel I-beams' numerical analysis performed using Finite Element Method implemented in ABAQUS software. An influence of bimoments restraints on critical moment of bending and load-bearing capacity of steel I-beams were investigated. Studied beams were bisymmetric I-section, single span and fork-supported at both ends. An external load was applied as a concentrated force in the middle of the span. Geometrically and materially nonlinear analysis with imperfections (GMNIA) was applied. The initial curvature was obtained from the first mode of Lateral-Torsional Buckling in LBA in ABAQUS software. The amplitude of initial imperfection was calculated accordingly to new LTB design rules and their derivation (the Snijder's approach). Results were compared to Eurocode's "General Formula" and LTBeamN software. Bimoment restraints were defined as steel plates connected to both flanges in a plane parallel to the element's web. The side plates working as a bimoment restraints were added to the computational model for different values of initial external load, which allowed to estimate its strengthening effect in existing I-beams.
\end{abstract}

\section{INTRODUCTION}

The steel I-beams are widely applied as bending members in building structures. In case of lack of additional lateral support the load-bearing capacity is often determined by lateraltorsional buckling of the element. The phenomenon is related i.e. with the buckling of the compressed flange of an I-beam and causes rotation along the longitudinal axis of the element. This initiates the warping effect which imposes rotation between two flanges caused by bimoments.

There are many parameters and physical characteristics that affect the lateral-torsional buckling. The most important are geometrical properties of beam's cross section (visible in the moments of the area) and its length. What is more, it is crucial to properly represent existing support in calculations. This requires to include warping degree of freedom and possibility of lateral bending at supports. Calculating load-bearing capacity of hot-rolled elements is similar to thin-walled members, where for a beam structure scheme 3 translational and 3 rotational degrees of freedom (DOF) are not sufficient to evaluate load-bearing capacity.

The slenderness is a parameter correlated to the length and cross-section of an element as well as type of its supports. The bigger the slenderness the more vulnerable the element is to lateral-torsional buckling. 


$$
\begin{aligned}
& \mathrm{M}_{\mathrm{cr}}=\mathrm{C}_{1} \frac{\pi^{2} \cdot \mathrm{E} \cdot \mathrm{I}_{\mathrm{z}}}{\left(\mathrm{k}_{\mathrm{z}} \cdot \mathrm{L}\right)^{2}}\left(\sqrt{\left(\frac{\mathrm{k}_{\mathrm{z}}}{\mathrm{k}_{\mathrm{w}}}\right)}{ }^{2} \frac{\mathrm{I}_{\omega}}{\mathrm{I}_{\mathrm{z}}}+\frac{\left(\mathrm{k}_{\mathrm{z}} \cdot \mathrm{L}\right)^{2} \cdot \mathrm{G} \cdot \mathrm{I}_{\mathrm{T}}}{\pi^{2} \cdot \mathrm{E} \cdot \mathrm{I}_{\mathrm{z}}}+\left(\mathrm{C}_{2} \cdot \mathrm{z}_{\mathrm{g}}-\mathrm{C}_{3} \cdot \mathrm{z}_{\mathrm{j}}\right)^{2}-\right. \\
& \left.-\mathrm{C}_{2} \cdot \mathrm{z}_{\mathrm{g}}-\mathrm{C}_{3} \cdot \mathrm{z}_{\mathrm{j}}\right)
\end{aligned}
$$

The next group of factors that influences the loss of stability are the parameters correlated to the type of load and its location in respect to the shear centre of the an I-beam.

The value of the maximum bending moment for an ideally-shaped element (without any imperfections) is called the critical moment ( $\left.\mathrm{M}_{\mathrm{cr}}\right)$. The new edition of the Eurocode 3 (CEN, 2006) does not provide any method of calculating it. However, a method can be found in the older versions of European Standard 3 (CEN, 1992) or other codes under the name of "General Formula".

Additional non-dimensional factors such as $\mathrm{C}_{1}, \mathrm{C}_{2}, \mathrm{C}_{3}$ or $\mathrm{k}_{\mathrm{z}}$ and $\mathrm{k}_{\mathrm{w}}$, are introduced as there is no simple calculation of critical moment for simply supported beam with non-fork support or non-centre alignment of the load. The general differential equation can be solved using trial and error method (Galambos, Surovek, 2008) or be approximated using e.g. Laplace transformation (Bosowski, 2015).

Factor $\mathrm{k}_{\mathrm{z}}$ and $\mathrm{k}_{\mathrm{w}}$ take values from 0.5 to 1.0 (where 0.5 means full fixity on both support and 1.0 means full pinned support).

In the research (Wierzbicki, 2018), the influence of endplates on the increase of the loadbearing capacity of an I-beam was examined. To achieve a significant impact it was necessary to strengthen the I-beam (type IS-300/150/S355JR L=5.0 m) with $40 \mathrm{~mm}$ thick endplates. For thickness of $80 \mathrm{~mm}$ the increase in the load-bearing capacity was almost unnoticeable. It is highly unusual to apply plates thicker than $40 \mathrm{~mm}$ in elements such as IPE160 - IPE400 or HEA equivalents, which are the most popular hot-rolled I-beams. It is hard to fix those plates using welding, because due to a big difference in thickness the thicker element requires preheating as to not influence the temperature of the welded joint.

To achieve significant increase of the load-bearing capacity of an I-beam under bending with lateral-torsional buckling it is possible to strengthen the cross-section with additional elements. Use of elements that connect top and bottom flanges in a plane of bending, allows to increase the value of Saint Venant's stiffness needed to reduce the warping effect. The examples of this solution are transverse ribs along the length of the beam, the X-shaped spacer, diagonal or orthogonal ribs (Chybiński, Garstecki, 2016 \& Chybiński, 2008) closed steel diaphragms or bimoment restraints (Kurzawa, 2006). This study focuses on the latter solution. The reduction of the $\chi_{\mathrm{LT}}$ coefficient required in some cases is sometimes impossible to achieve due to already existing loads or limited space for enlarging the compressed flange (generally the top one) which can be fixed with other elements such as concrete slabs, trapezoidal sheet or sandwich panels. Increasing the load-bearing capacity of an I-beam using bimoments restraints requires only a small amount of additional steel and simple welding in comparison to other methods of strengthening which require extensive works.

This paper is an extension of previous studies (Wierzbicki, 2020) which investigated the effect of restraint on load-bearing capacity of an I-beam.

\section{MATERIALS AND METHODS}

\subsection{Geometrical and material properties of the beam}

A hot-rolled, steel I-beams IPE200 with three lengths of $2.5 \mathrm{~m}, 5.0 \mathrm{~m}$ and $7.5 \mathrm{~m}$ were taken into consideration. They are simply and fork supported at the ends. The load is applied as a concentrated force in the middle of the span, located at the top flange in the plane of the web. The I-beams were modelled using bilinear stress-strain model of S355JR steel. To enhance the load-bearing capacity of bending, four longitudinal stiffeners were rigidly connected to inner sides of the flanges. Dimensions of each plate are $183 \mathrm{~mm} \times 183 \mathrm{~mm}$ with $20 \mathrm{~mm}$ thickness. Due to fork and pinned support at both ends the maximum warping occurs 
there. Due to this additional plates were fixes at supports. That location proved to be the most efficient (Piotrowski, Szychowski, 2015 \& Iwicki, 2010).

\subsection{Methods}

Calculations were conducted in ABAQUS CAE environment. The beams were modelled using $25 \mathrm{~mm}$ S4R shell elements. First of all, for each beam the shape was determined for a normal mode and the geometry was assumed based on this result. Similar approach can be seen e.g. in (Giżejowski, 2016 \& 2017). The next step of the analysis was to apply a load and in some cases additional longitudinal stiffeners for different load values. Then, non-linear analysis (using the Riks method) was carried out to calculate the maximum value of load that can be applied to model. To simplify the calculations and due to the fact, that at supports the value of bending stress in I-beam is rather insignificant, the influence of welding was omitted. Authors will consider this phenomenon in further studies.

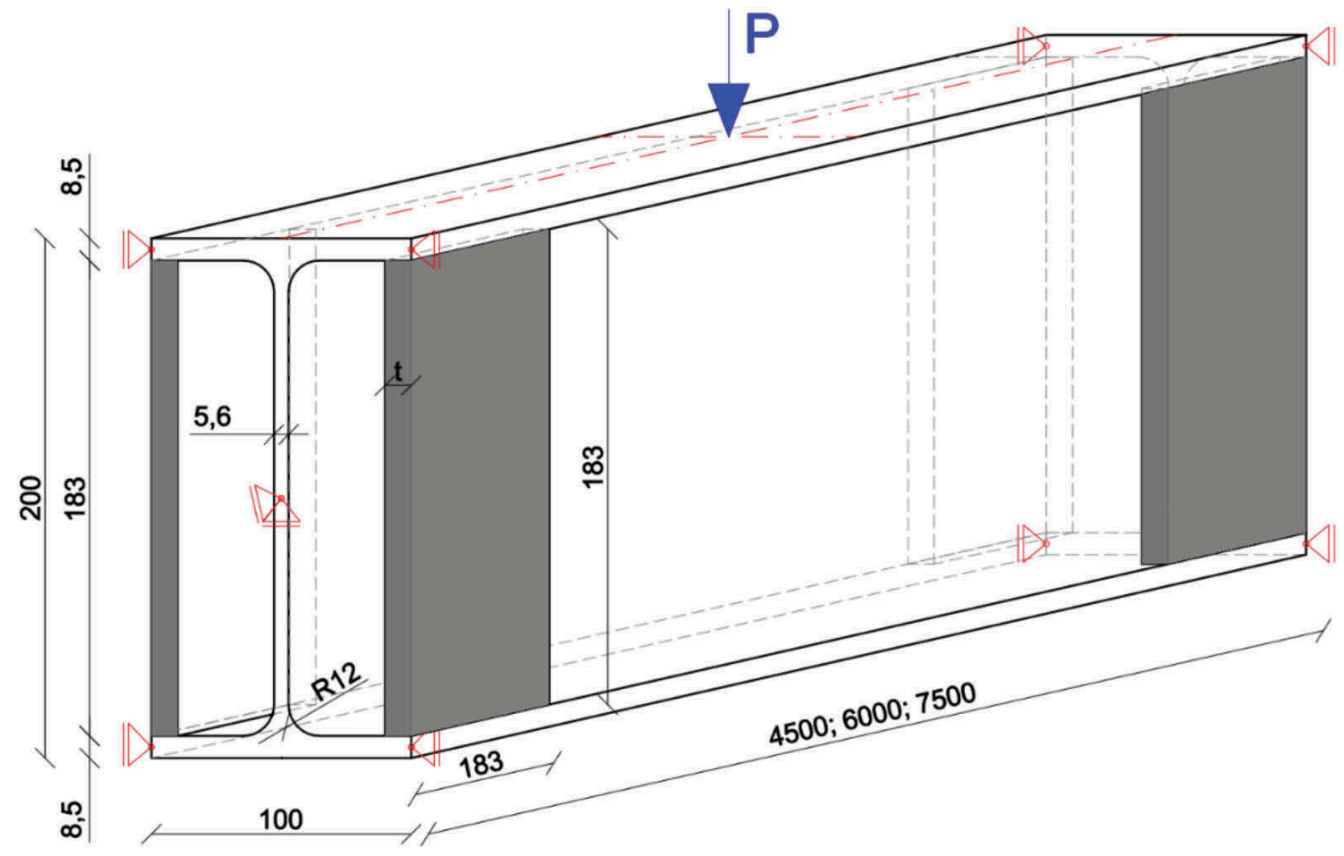

Figure 1. Geometrical characteristics of I-beams with bimoment restraints, similar to (Wierzbicki, 2020).

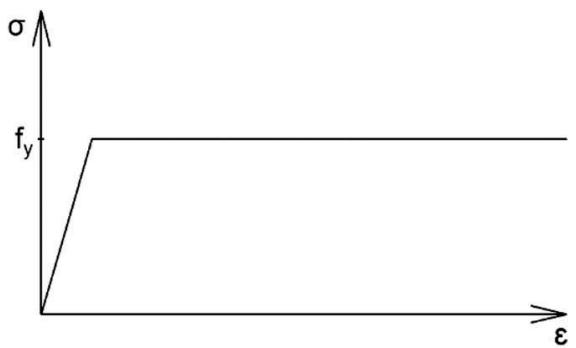

Figure 2. Stress-strain relation included in the calculations, as in (Wierzbicki, 2020).

To show the influence of added restraints at certain load levels the outcomes were presented as a relation of the load and lateral displacement of a node in the middle of the span. 
This analysis includes non-linear geometrical and material imperfections (GMNIA). The value of geometrical imperfection's amplitude was calculated based on (Rykaluk, 2012 \& Snijder, 2018):

$$
\mathrm{e}_{0, \mathrm{~d}}=\alpha_{\mathrm{LT}}\left(\bar{\lambda}_{\mathrm{LT}}-0.2\right) \frac{\mathrm{M}_{\mathrm{Rk}}}{\mathrm{N}_{\mathrm{Rk}}}
$$

where $\alpha_{L T}-$ imperfection factor, for $\mathrm{h} / \mathrm{b}>1.2$ :

$$
\alpha_{\mathrm{LT}}=0.12 \sqrt{\mathrm{W}_{\mathrm{el}, \mathrm{y}} / \mathrm{W}_{\mathrm{el}, \mathrm{z}}} \leq 0.34
$$

\section{RESULTS AND DISCUSSION}

\subsection{Results for a beam with $L=2.5 \mathrm{~m}$}

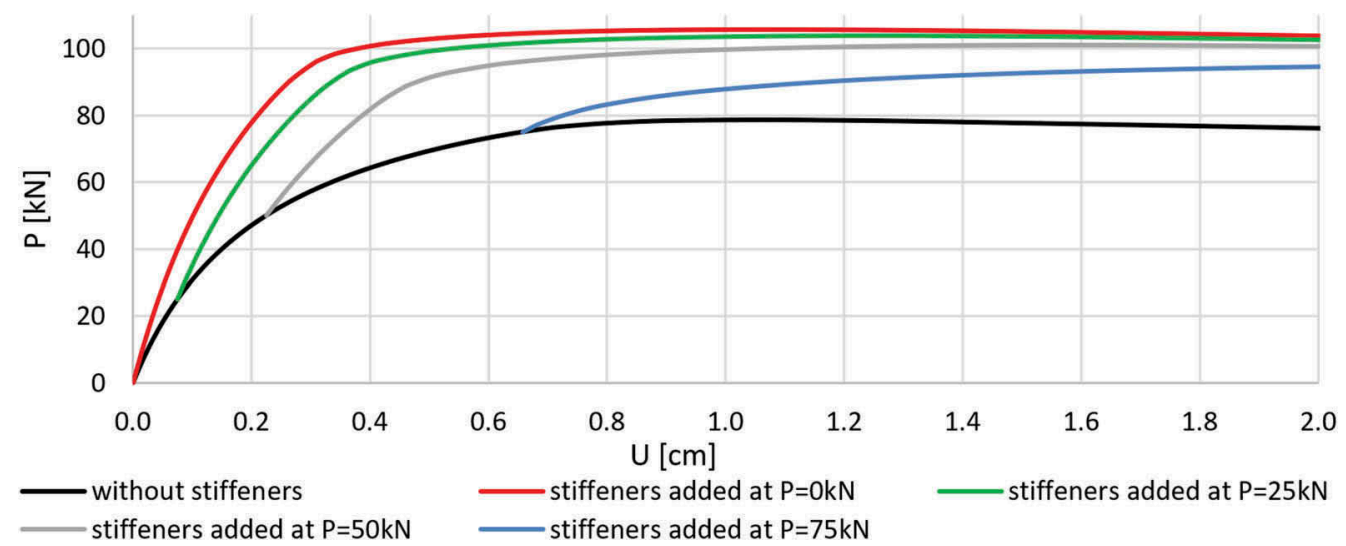

Figure 3. Correlation between load and lateral displacement for $2.5 \mathrm{~m}$ I-beam.

\subsection{Results for a beam with $L=5.0 \mathrm{~m}$}

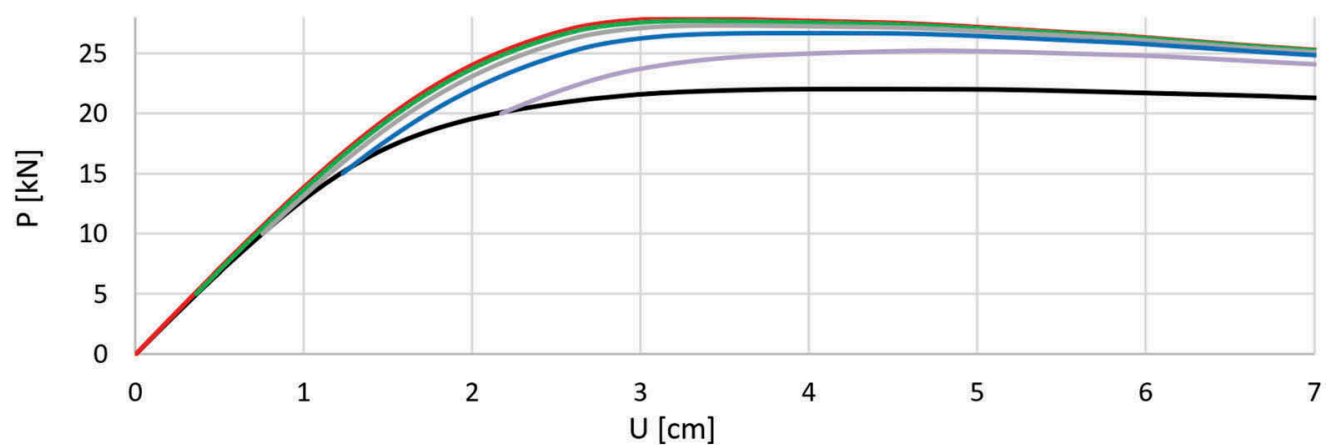

\footnotetext{
without stiffeners

stiffeners added at $\mathrm{P}=10 \mathrm{kN}$
}

- stiffeners added at $\mathrm{P}=0 \mathrm{kN}$

stiffeners added at $\mathrm{P}=5 \mathrm{kN}$

stiffeners added at $\mathrm{P}=15 \mathrm{kN}$ stiffeners added at $P=20 \mathrm{kN}$

Figure 4. Load versus lateral displacement of node from the top flange in the middle span for $5.0 \mathrm{~m}$ I-beam. 


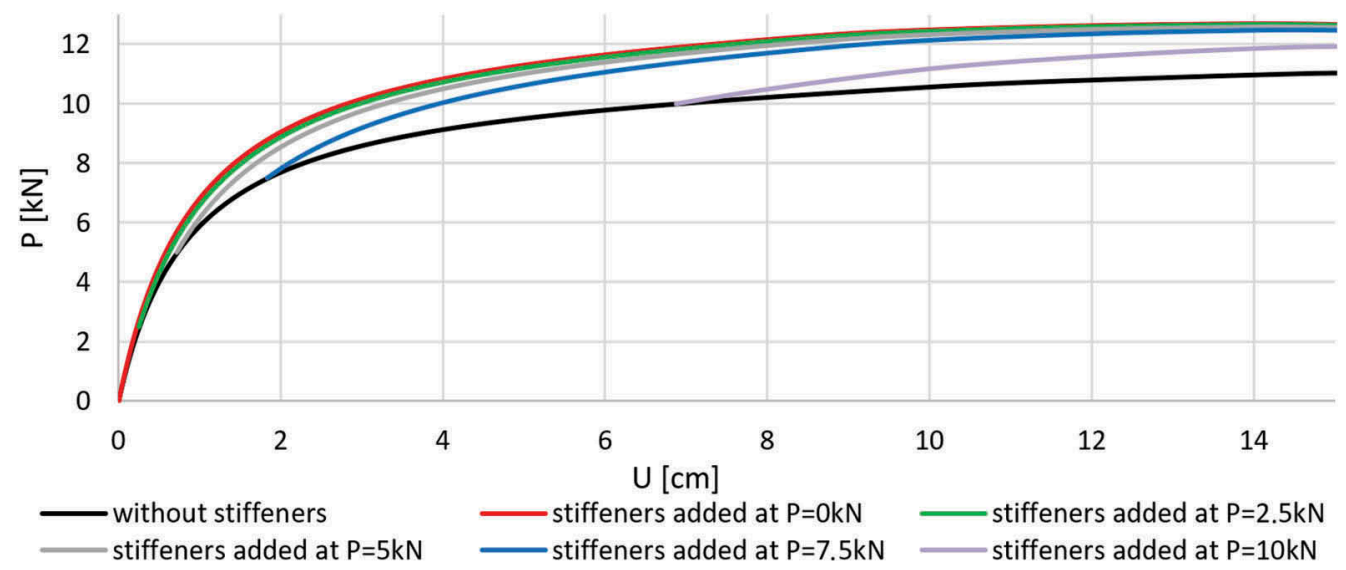

Figure 5. Load versus lateral displacement of node from the top flange in the middle span for $7.5 \mathrm{~m}$ I-beam.

\subsection{Comparison and discussion}

The shorter the beam, the bigger differences between load bearing capacity after strengthening. It can be seen that addition of restraint at the location of rapidly growing lateral displacement can strengthen the beam significantly. Nevertheless, adding the restraints to the beam which is almost at its load bearing capacity limit should be done using special safety measures, because during welding of the restraints there is always a danger of weakening the construction due to post welding stress and reduction of yield strength due to growth of temperature. The less loaded the construction is during strengthening with bimoment restraints the bigger load bearing capacity will be reached in the end.

The values of elastic critical moment of bending without any stiffeners were calculated in three ways (Table 1). First of all, the same model as described in paragraph 2.1 was taken into consideration. Secondly, the same geometrical parameters of beams, supports and load were modelled in LTBeam software. Then, calculation were conducted according to the General Formula. The biggest differences can be spotted for the shortest beam. The $2.5 \mathrm{~m}$ IPE200 is too short to be analyzed properly (without significant differences to more complex models) using beam object (as in LTBeam) or without taking into consideration shell structure in a membrane state $(\mathrm{L} / \mathrm{h}=12.5<20)$.

Table 2 shows a comparison between elastic critical moment values for models with longitudinal restraints $183 \times 183 \times 20 \mathrm{~mm}$ (as described in paragraph 2.1) and model with rigid, nondeformable plates. It can be seen that the solution gives similar results as a full rigid support for warping. Results from LTBeam and ABQAUS model are almost the same (with the biggest deviation between them for the shortest beam).

Table 1. Values of the elastic critical moment for beams without imperfections and longitudinal stiffeners - buckle modes.

\begin{tabular}{llll}
\hline Length $[\mathrm{m}]$ & $\begin{array}{l}\text { ABAQUS } \\
\text { shell S4R }\end{array}$ & LTBeam & $\begin{array}{l}\text { General } \\
\text { Formula eq. (1) }\end{array}$ \\
\hline 2.5 & 60.61 & 63.54 & 64.19 \\
5.0 & 29.39 & 29.90 & 30.33 \\
7.5 & 20.03 & 20.32 & 20.65 \\
\hline
\end{tabular}


Table 2. Values of the elastic critical moment for beams without imperfections and with longitudinal stiffeners - buckle modes.

\begin{tabular}{llll}
\hline Length $[\mathrm{m}]$ & $\begin{array}{l}\text { ABAQUS shell S4R } \\
\text { stiffeners 183x183x20 mm }\end{array}$ & $\begin{array}{l}\text { ABAQUS shell } \\
\text { S4R rigid stiffeners }\end{array}$ & $\begin{array}{l}\text { LTBeam rigid } \\
\text { stiffeners }\end{array}$ \\
\hline 2.5 & 109.20 & 113.28 & 115.49 \\
5.0 & 39.74 & 39.85 & 40.22 \\
7.5 & 24.02 & 24.09 & 24.29 \\
\hline
\end{tabular}

\section{CONCLUSIONS}

Strengthening the steel I-beam by adding bimoment restraints at the ends of a simply and fork supported beam causes a significant increase in the critical moment of bending and - as a consequence - the load bearing capacity of an element. The use of typical $10-20 \mathrm{~mm}$ plates is sufficient to limit the warping of the element. There is no need to increase the thickness of the plates.

The increase of load-bearing capacity after strengthening a loaded beam is correlated to its slenderness. The more slender the beam the lower the strengthening effect will occur when the load is applied (except for stocky beams, where load-bearing capacity of element is defined by plastic resistance in major axis bending). The more load is applied to the beam during strengthening the lower influence on stability can be obtained. The bigger the load before adding restraints the smaller the increase of load bearing capacity at bending. It is important to strengthen the beam before reaching the plastic operation, because then the strengthening effect is the most significant. For the purpose of this study an assumption was made, that welding the bimoment restraints at the ends of a beams can be omitted in modelling due to negligible values of stresses there. However, it will be taken into consideration during further studies. That problem require more complex analysis.

\section{REFERENCES}

Chybiński, M. \& Farkas, J. \& Garstecki, A. \& Jarmai, K. \& Rzeszut, K. 2008. Optimization of Steel Beams and Columns for Variable Rib Configuration: International Conference Proceedings 2008, Miskolc, Hungary, April 24-26, 2008: 113-118.

Chybiński, M. \& Garstecki, A. 2016. Diagonal versus orthogonal ribs in stability of steel I beams: Procedia Engineering 172 (2017): 172-177.

EN 1993-1-1.2006.Eurocode 3: Design of steel structures - Part 1-1: General rules and rules for buildings: CEN.

prEN 1993-1-1. 1992. Eurocode 3: Design of steel structures - Part 1-1: General rules and rules for buildings: CEN.

EN 1999-1-1. 2006. Eurocode 9: Design of aluminium structures - Part 1-1: General structural rules: CEN.

Galambos, T.V. \& Surovek, A. E. 2008. Structural Stability of Steel: Concepts and Applications for Structural Engineers: John Wiley \& Sons, Inc: 236-289.

Giżejowski, M. \& Szczerba, R. \& Gajewski, M. 2017. Influence of imperfections on LTB resistance of steel rolled and welded beams: JCEAA, t. XXXIV, z.64 (3/I/17): 447-460 (in Polish).

Giżejowski, M. \& Szczerba, R. \& Gajewski, M. 2016. FEM models and simulation methods in lateraltorsional buckling analysis of steel elements: JCEAA, t. XXXIII, z.63 (1/I/16), 339-346, 2016 (in Polish).

Gosowski B. 2015. Bending and torsion of thin walled metal structures: Oficyna Wydawnicza Politechniki Wrocławskiej (in Polish).

Iwicki, P. 2010. Sensivity analysis of buckling loads of bisymetric I-section columns with bracing elements: Archives of Civil Engineering, Vol. LVI, Issue 1: 69-88.

Kurzawa, Z. \& Rzeszut, K. \& Szumigała, M. \& Chybiński M. 2006. Influence of endplates on the Critical Moment of of I-beams: Inżynieria i Budownictwo Nr 3/2006: 163-166 (in Polish).

Piotrowski, R., Szychowski, A. 2015. Lateral-torsional buckling of beams elastically restrained against warping at supports: Archives of Civil Engineering, Vol. LXI, Issue 4: 155-174. 
Rykaluk, K. 2012. Stability issues of metal structures: Dolnośląskie Wydawnictwo Edukacyjne: 176-201 (in Polish).

Snijder, H.H. \& van der Aa, R.P. \& van Hove, B.W.E.M. 2018. Lateral torsional buckling design imperfections for use in non-linear FEA: Steel Construction: Design and Research, 11(1): 49-56.

Wierzbicki, K. 2018. Influence of endplates on the value of critical moment 2018: International Interdisciplinary PhD Workshop (IIPhDW): 142-146.

Wierzbicki, K. 2020. Influence of bimoment restraints on the load-bearing capacity of a steel I-beam: CEER 2020;30 (4): 33-47. 